\title{
The vertical distribution of aerosols, Saharan dust and cirrus clouds in Rome (Italy) in the year 2001
}

\author{
G. P. Gobbi, F. Barnaba, and L. Ammannato \\ Istituto di Scienze dell' Atmosfera e del Clima, CNR, Roma, Italy \\ Received: 9 September 2003 - Published in Atmos. Chem. Phys. Discuss.: 14 November 2003 \\ Revised: 16 February 2004 - Accepted: 17 February 2004 - Published: 25 February 2004
}

\begin{abstract}
A set of 813 lidar profiles of tropospheric aerosol and cirrus clouds extinction and depolarization observed in Rome, Italy, between February 2001 and February 2002 is analyzed and discussed. The yearly record reveals a meaningful contribution of both cirrus clouds (38\%) and Saharan dust (12\%) to the total optical thickness (OT) of 0.26 , at $532 \mathrm{~nm}$. Seasonal analysis shows the planetary boundary layer (PBL) aerosols to be confined below $2 \mathrm{~km}$ in winter and $3.8 \mathrm{~km}$ in summer, with relevant OT shifting from 0.08 to 0.16 , respectively. Cirrus clouds maximise in spring and autumn, in both cases with average OT similar to the PBL aerosols one. With the exception of winter months, Saharan dust is found to represent an important third layer mostly residing between PBL aerosols and cirrus clouds, with yearly average $\mathrm{OT} \approx 0.03$. Saharan dust and cirrus clouds were detected in $20 \%$ and in $45 \%$ of the observational days, respectively. Validation of the lidar OT retrievals against collocated sunphotometer observations show very good agreement. These results represent one of the few yearly records of tropospheric aerosol vertical profiles available in the literature.
\end{abstract}

\section{Introduction}

Current global radiative balance estimates attribute to atmospheric aerosols a negative forcing comparable and opposite to the one of greenhouse gases (e.g. Penner et al., 2001). This is the result of a direct effect, produced by the aerosol scattering and absorption of solar radiation, and of an indirect (possibly larger) effect related to the aerosol capability of affecting cloud formation and radiative properties (e.g. Ramanathan et al., 2001). These effects take place mainly within and above the planetary boundary layer (PBL), re-

Correspondence to: G. P. Gobbi

(g.gobbi@isac.cnr.it) spectively. The PBL is the region where most of the atmospheric aerosol mass is located (e.g. Jaenicke, 1992). At the same time, it is well established that large amounts of mineral dust from arid regions of the Earth (e.g. Prospero et al., 2002) are lifted well into the free troposphere (e.g. Sakai et al., 2000; Gobbi et al., 2000; Sassen, 2002) and transported over thousands of kilometers (e.g. Duce et al., 1980; Prospero et al., 1983; Moulin et al., 1998; Karyampudi et al., 1999).

Such a variable height-dependent distribution explains why a large part of the indetermination in forecasting the aerosol radiative impact derives from differences in the aerosol vertical profile employed in models (e.g. Penner et al., 2001). In fact, our knowledge about height-resolved aerosol properties over long-term periods is still rather poor and, as also stated in Penner et al. (2001), mostly limited to localized observations performed by balloon or aircraftborne instruments (e.g. Hofmann, 1993, de Reus et al., 2001) or by lidar systems. In fact, lidar observations represent a convenient technique to collect long-term aerosol records (e.g. Hamonou et al., 1999; Balis et al., 2000; Franke et al., 2001; Matthias and Bosenberg, 2002; Schneider and Eixmann, 2002). Nevertheless, lidar-derived climatological profiles of aerosol optical properties in the whole troposphere are still uncommon in the literature. Lidar studies often address aerosol properties integrated over the whole PBL (e.g. Matthias and Bosenberg, 2002; Del Guasta, 2002), or over the lower troposphere (e.g. Sakai et al., 2000; Balis et al., 2000; Franke et al., 2001; Schneider and Eixmann, 2002). Conversely, lidar profiles are mostly presented in case studies of specific aerosol events (e.g. Hamonou et al., 1999; Murayama et al., 2001; Muller et al., 2003; De Tomasi and Perrone, 2003). To our knowledge, no climatological profiles of tropospheric aerosol extinction and depolarization are currently available in the literature. This shortcoming will be reduced when systematic, space-borne lidar experiments as CALIPSO (NASA-CNES, http://www-calipso.larc. 
nasa.gov) and Earthcare (ESA, http://www.esa.int) will become operational. Still, ground-based observations will remain necessary to provide validated and continuous inputs to climate models.

In this paper we present a one-year record of aerosol and cirrus cloud observations made at the southern outskirts of Rome, Italy $\left(41.840^{\circ} \mathrm{N}-12.647^{\circ} \mathrm{E}, 130 \mathrm{~m}\right.$ a.s.l.) by means of a polarization-sensitive lidar operated in both day and nighttime conditions. In this semi-rural location we expect the presence of continental plus combustion-originated aerosols, leading to moderately polluted PBL conditions. Furthermore, as in the whole Mediterranean region, we expect a strong input of mineral dust from the Sahara desert (e.g. Moulin et al., 1998). With the aim of providing data suitable for use in radiative transfer models, the lidar-derived profiles of optical and physical properties of aerosols and cirrus clouds will be discussed in terms of both their seasonal variability and yearly average characterization.

\section{Methods}

The lidar system employed in our observations exploits a frequency-doubled Nd:YAG laser, emitting $532 \mathrm{~nm}$, planepolarized, $30 \mathrm{~mJ}$ pulses at $10 \mathrm{~Hz}$. Two co-located telescopes, a $10 \mathrm{~cm}$ and a $25 \mathrm{~cm}$ one, allow to collect a full backscatter profile between $300 \mathrm{~m}$ and $14 \mathrm{~km}$ from the ground (e.g. Gobbi et al., 2000). Parallel and cross-polarized components (with respect to the laser polarization plane) of the backscatter signal are collected and recorded at both telescopes by photon-counting detection chains. Each lidar profile is obtained by averaging 6000 laser shots, has a maximum vertical resolution of $37.5 \mathrm{~m}$ and is calibrated at an aerosol-free height against a monthly standard atmosphere, obtained from a ten-year climatology of radio-soundings launched $30 \mathrm{~km}$ West of our site.

Signal analysis is performed according to the approach outlined in Gobbi et al. (2002). In particular, the lidar equation (e.g. Measures, 1984) is solved numerically and the ratio between aerosol extinction and backscatter coefficients $\left(\sigma_{a} / \beta_{a}\right)$ needed to retrieve both $\beta_{a}$ and $\sigma_{a}$ from the single-wavelength lidar profile is determined by means of aerosol models providing a functional relationship $\sigma_{a}=$ $f\left(\beta_{a}\right)$ (e.g. discussion below). The procedure to retrieve the aerosol backscatter $\beta_{a}(\mathrm{z})$ at each level $(\mathrm{z})$ of the profile can be summarized as follows: 1) The molecular backscatter profile $\beta_{m}(\mathrm{z})$ is computed from the model atmosphere. The lidar trace is calibrated against this $\beta_{m}(\mathrm{z})$ profile at an aerosol-free level selected by visual analysis of the signal. The calibrated lidar signal then represents the nonattenuated total backscatter profile $\left.\beta_{t o t}(\mathrm{z})=\beta_{m}(\mathrm{z})+\beta_{a}(\mathrm{z}) ; 2\right)$ the aerosol backscatter $\beta_{a}(\mathrm{z})$ at each measurement point is determined as $\left.\beta_{a}(\mathrm{z})=\beta_{\text {tot }}(\mathrm{z})-\beta_{m}(\mathrm{z}) ; 3\right)$ the aerosol extinction $\sigma_{a}(\mathrm{z})$ at each measurement point is obtained from the $\sigma_{a}=f\left(\beta_{a}\right)$ model relationship on the basis of the aerosol backscatter $\beta_{a}(\mathrm{z})$ computed at step $\left.2 ; 4\right)$ at each measurement point the calibrated signal $\beta_{t o t}(\mathrm{z})$ is corrected for both the aerosol and molecular extinction encountered below that point, then providing a new extinction-corrected profile $\beta_{t o t}^{\prime}(\mathrm{z})$; 5) steps $1-4$ are iterated until convergence on integrated aerosol backscatter is reached, according to the condition: $\sum_{i}\left|\beta_{a}^{\prime}\left(\mathrm{z}_{i}\right)-\beta_{a}\left(\mathrm{z}_{i}\right)\right| / \sum_{i} \beta_{a}\left(\mathrm{z}_{i}\right) \leq 10^{-3}$, with $i$ indicating the $i$-th discrete level of the lidar profile. Errors in the retrieval of $\beta_{a}(\mathrm{z})$ depend on range and measurement conditions as background noise, accuracy of the model atmosphere, of the $\sigma_{a} / \beta_{a}$ ratio and of the calibration (e.g. Russell et al., 1979; Measures, 1984). By taking into account all these parameters and following the error analysis method of Russell et al. (1979), typical errors of $\mathrm{d} \beta / \beta \approx 20 \%$ are found to characterize the backscatter coefficients presented in this paper.

For this analysis, a continental aerosol model (Barnaba and Gobbi, 2004) has been employed as default, while the mineral dust model (Barnaba and Gobbi, 2001) is used during Saharan dust events. Presence of dust is predicted by means of forecast model analysis (e.g. the DREAM model of the Euro Mediterranean Centre for Insular Coastal Dynamics of Malta: http://www.icod.org.mt/), confirmed by the lidar depolarization trace, and checked on the basis of backtrajectories. This analysis of particles origin will be further discussed in Sect. 3. Finally, an ice particles model (Gobbi, 1995 ) is employed for the signal analysis in regions where cirrus clouds are detected. The mean error of the extinction coefficients obtained by these retrievals is of the order of 20$50 \%$ (typically $35 \%$ ), depending on measurement conditions and aerosol type, e.g. Barnaba and Gobbi (2001), Gobbi et al. (2003).

The lidar-derived variables we will discuss are: 1) the $532 \mathrm{~nm}$ aerosol extinction coefficient $\left.\sigma_{a}\left(\mathrm{~km}^{-1}\right), 2\right)$ the linear depolarization ratio $\mathrm{D}$, and 3$)$ the backscatter ratio $\mathrm{R}=\left(\beta_{a}+\right.$ $\left.\beta_{m}\right) / \beta_{m}$. In our analysis, $\mathrm{D}$ is defined as the ratio between cross $(\perp)$ and parallel $(/ /)$ polarized backscatter signals, i.e. $\mathrm{D}=\mathrm{S}_{\perp} / \mathrm{S}_{/ /} \propto\left(\beta_{\perp a}+\beta_{\perp m}\right) /\left(\beta_{/ / a}+\beta_{/ / m}\right)$. Therefore, $\mathrm{D}$ is a weighted contribution of molecular and aerosol depolarization. While spherical particles as liquid aerosols or small cloud droplets do not generate a depolarized signal, nonspherical (solid) ones as dust or cirrus clouds show particle depolarization $\mathrm{D}_{a}=\left(\beta_{\perp a}\right) /\left(\beta_{/ / a}\right) \approx 40-60 \%$ (e.g. Sassen, 1991; Mishchenko and Sassen, 1998; Gobbi et al., 2000). This behavior provides a powerful tool to infer the particulate thermodynamic phase. In our analysis we shall employ total depolarization $\mathrm{D}$ rather than particle depolarization $\mathrm{D}_{a}$, since the latter becomes very unstable at low aerosol contents (small $\beta_{/ / a}$ ). In molecular (aerosol-free) scattering conditions our system detected $\mathrm{D} \approx 1.4-2.0 \%$.

We shall also discuss the vertical build-up of the optical thickness (OT) at $532 \mathrm{~nm}$, obtained by integration over altitude $(\mathrm{z})$ of the retrieved $\sigma_{a}(\mathrm{z})$ profiles $\left(\mathrm{OT}(\mathrm{z})=\int_{0}^{z} \sigma_{a}\left(\mathrm{z}^{\prime}\right)\right.$ dz'). To validate such results, lidar-derived OT will be compared to collocated, same wavelength sunphotometer 
(a)

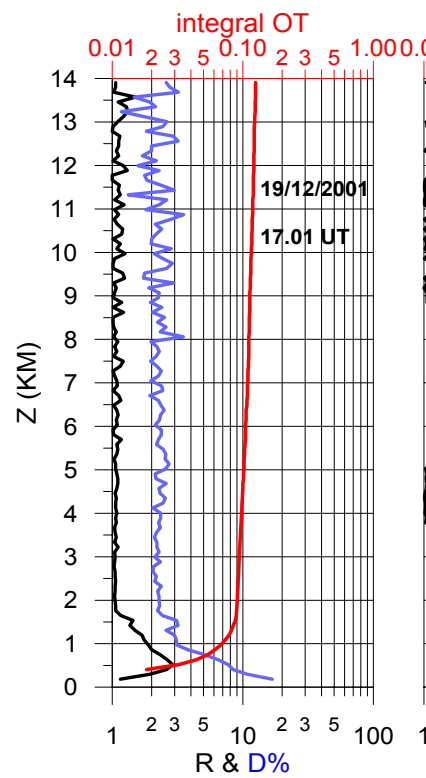

(b)

integral OT

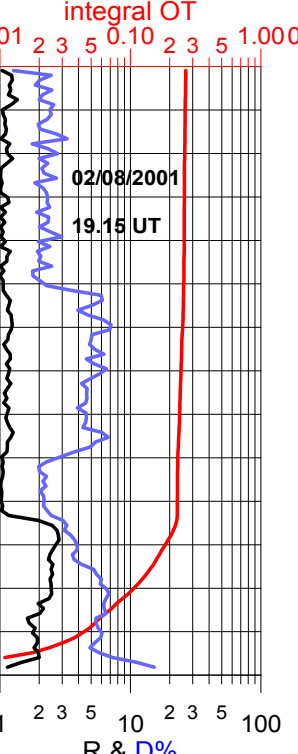

(c)

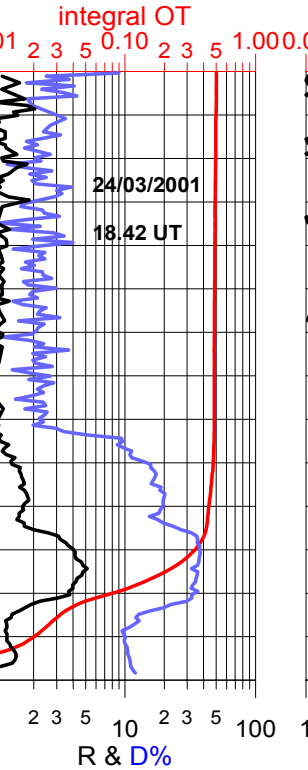

(d)

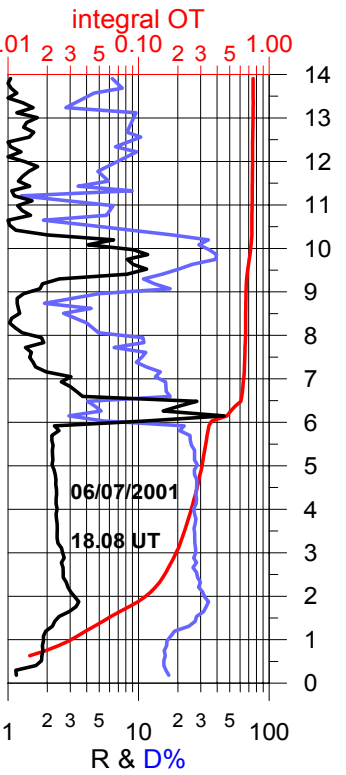

Fig. 1. Typical lidar profiles (at $532 \mathrm{~nm}$ ) representative of: (a) clear winter conditions; (b) summer PBL aerosol and pre-dust conditions; (c) spring dust conditions, and (d) summer dust, liquid cloud and cirrus cloud conditions. The three curves reported in each plot represent vertical profiles of backscatter ratio $\mathrm{R}$ (black line), depolarization ratio $\mathrm{D}(\%)$ (blue line), and (red line) the integral (from ground) of the extinction coefficient, i.e. OT(z), respectively.

measurements made at our Rome Tor Vergata site in the framework of AERONET (the NASA Aerosol Robotic Network: http://aeronet.gsfc.nasa.gov). These comparisons will employ the "cloud-screened", i.e. cloud and cirrus-free OT measurements made by our sunphotometer within one hour from the lidar one. Expected accuracy of the sunphotometer OT observations is \pm 0.02 (e.g. Holben et al., 1998).

\section{Observations}

A set of 993 lidar profiles was retrieved over 207 measurement days between 15 February 2001 and 14 February 2002. Average sampling rate of this record is 4.8 profiles/day. Measurements were carried-out at non-synchronous times between 7:00 am and 9:00 pm (UTC), usually spaced by 2$3 \mathrm{~h}$. Here we shall discuss the cloudless portion of the observations (813 profiles gathered over 198 days), which includes PBL aerosol, Saharan dust and cirrus cloud conditions. Statistical analysis of the observations will be carried out by both averaging over the whole dataset (yearly average) and over seasonal periods (i.e. December to February (DJF), March to May (MAM), June to August (JJA) and September to November (SON)). In each case, four average profiles will be provided, referring respectively to: 1) the total set of 813 observations (TOT); 2) the observations collected in no-dust conditions (ND); 3) the observations collected in no-cirrus cloud conditions (NC), and 4) Saharan dust affected obser-
Table 1. Synopsis of the four average profiles discussed in the paper. Number of lidar traces considered in averages is reported in Table 2.

\begin{tabular}{lll}
\hline Label & Averaged lidar profiles & Curve color \\
\hline TOT & All profiles & blue \\
ND & No Saharan-dust-affected profiles (TOT-SD) & green \\
NC & No cirrus-affected profiles (TOT-cirrus) & pale blue \\
SD & Saharan dust-affected profiles only & red \\
\hline
\end{tabular}

vations (SD). It is worth noticing that lidar traces containing cirrus features are only excluded in the $\mathrm{NC}$ average profile. The synopsis of the four average profile definitions is given in Table 1.

There is no clear-cut way of discriminating between various aerosol and cloud types on the basis of lidar traces alone. However, some good inference can be done employing the polarization lidar data. Our classification has been performed via manual single-profile analysis, comparison with model aerosol forecasts and, when necessary, by back-trajectory analysis. To illustrate the lidar response to various atmospheric conditions, we present in Fig. 1 four representative profiles. Three curves are reported in each plot, representing respectively vertical profiles of backscatter ratio $\mathrm{R}$ (black line), depolarization ratio, D\% (blue line) and the integral (from the ground) of the extinction coefficient, i.e. the optical 

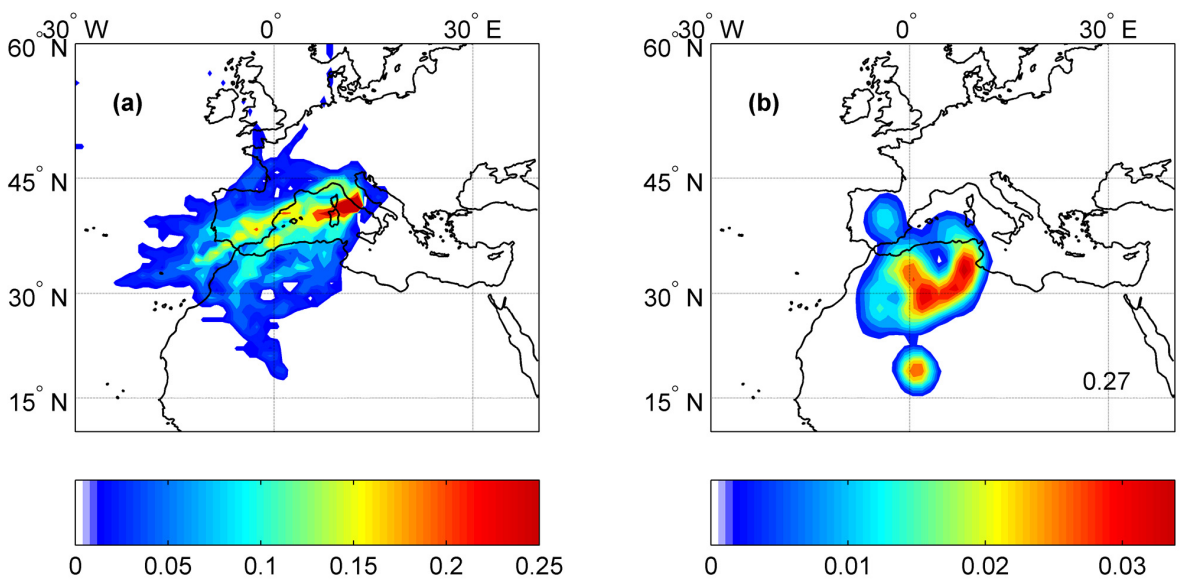

Fig. 2. Backtrajectory analysis of airmasses ending between 3 and $4 \mathrm{~km}$ over Rome, during the acquisition of the 180 lidar profiles classified as Saharan dust-affected (SD): (a) geographical density of the computed 1,830 backtrajectories; (b) geographical density of backtrajectories transit (for at least three hours) within the atmospheric mixed layer computed by the HYSPLIT code (Draxler and Rolph, 2003). Densities in Fig. $2 \mathrm{~b}$ are normalized to the total number of backtrajectories entering the mixed-layer, $\mathrm{N}_{M L}$. The ratio between $\mathrm{N}_{M L}$ and the total number of backtrajectories (1830) is reported in the bottom-right corner of Fig. 2b.

Table 2. Number of observational days (OD) and averaged lidar profiles (LP, in brackets), classified by period of measurement and particulate type. The PBL aerosol case includes dust-less and cirrus-less profiles only. The ND and NC cases can be computed as TOT-Dust and TOT-Cirrus, respectively.

\begin{tabular}{cccccc}
\hline Condition & YEAR & DJF & MAM & JJA & SON \\
& OD (LP) & OD (LP) & OD (LP) & OD (LP) & OD (LP) \\
\hline Cloudless (TOT) & $198(813)$ & $45(145)$ & $52(193)$ & $45(232)$ & $56(243)$ \\
PBL aerosol & $163(428)$ & $39(122)$ & $34(49)$ & $41(140)$ & $49(117)$ \\
Dust (SD) & $39(183)$ & $0(0)$ & $15(57)$ & $12(65)$ & $12(61)$ \\
Cirrus (CIR) & $89(202)$ & $13(23)$ & $34(87)$ & $15(27)$ & $27(65)$ \\
\hline
\end{tabular}

thickness OT(z) (red line). Figure 1a depicts a typical winter aerosol condition, with $\mathrm{OT} \approx 0.1$, and boundary layer aerosols confined below $2 \mathrm{~km}$. Depolarization in the aerosol-free region is of the order of $2 \%$. Conversely, Fig. $1 \mathrm{~b}$ reports a summer case in which PBL aerosols reach up to $3.7 \mathrm{~km}$, an effect due to the stronger convective mixing typical of the warmer seasons. In fact, the increase in backscatter and decrease in depolarization observed at $2.8-3.5 \mathrm{~km}$ reveals the level of the "entrainment layer", the region topping the PBL where stratocumulus clouds usually form (e.g. Stull, 1988). This profile also illustrates the sensitivity of the depolarization trace to the presence of non-spherical particles. In fact, at that time (19.15 UT of 2 August, 2001) a Saharan dust plume was reaching our site travelling between 5 and $9 \mathrm{~km}$. Even if the dust load was still very low $\left(\mathrm{R}<1.2, \sigma_{a} \approx 0.007 \mathrm{~km}^{-1}\right)$, the sharp increase in depolarization clearly reveals the presence of non-spherical particles.

Examples of the aerosol load associated to fully developed dust events are reported in Figs. 1c and d, respectively. Both profiles show the correlated increase in both $\mathrm{R}$ and $\mathrm{D}$ typical of such events $(\mathrm{R} \approx 2-5, \mathrm{D} \approx 10-45 \%)$, leading to optical thicknesses of the order of 0.3-0.5. Saharan dust has depolarization levels similar to cirrus clouds, while backscatter ratios are mostly one order-of-magnitude smaller and lifetimes one order-of-magnitude larger. Together with a broader vertical extent of Saharan dust layers, all these features allow for a good discrimination between cirrus clouds and dust. In addition, Fig. 1d shows the behavior of the lidar traces in the presence of liquid and frozen clouds: the sharp increase in $\mathrm{R}$ due to the presence of clouds is anticorrelated with respect to $\mathrm{D}$ in the first case $(6-6.5 \mathrm{~km})$ and correlated with $\mathrm{D}$ in the cirrus case $(9-10.5 \mathrm{~km})$. These few examples well illustrate how the lidar-observed scattering properties can allow for discriminating the various types of particles suspended in the atmosphere.

The number of observational days and lidar profiles catalogued per aerosol category and per season is reported in Table 2. Saharan dust was detected in $20 \%$ of the 198 operational days, distributed over fourteen dust events. The measurement rate in dust conditions, was of 4.7/day (e.g. Table 2). Maximum occurrence of dust was registered in spring-summer (about 28\%), with no events in winter. Due to coexistence with clouds, approximately 12 days of dust conditions have not been included in this cloud-screened statistics. Cirrus clouds were detected in 89 days, i.e. in $45 \%$ of the operational days, with maximum and minimum incidence registered in Spring $(65 \%)$ and Winter-Summer $(\approx 30 \%)$, respectively. The lower rate of cirrus clouds observations (2.3/day) reflects the short lifetime of these layers. It is worth mentioning that a three-year (1997-1999) cirrus cloud climatology based on night-time lidar measurements made in southern France (Goldfarb et al., 2001) shows some 

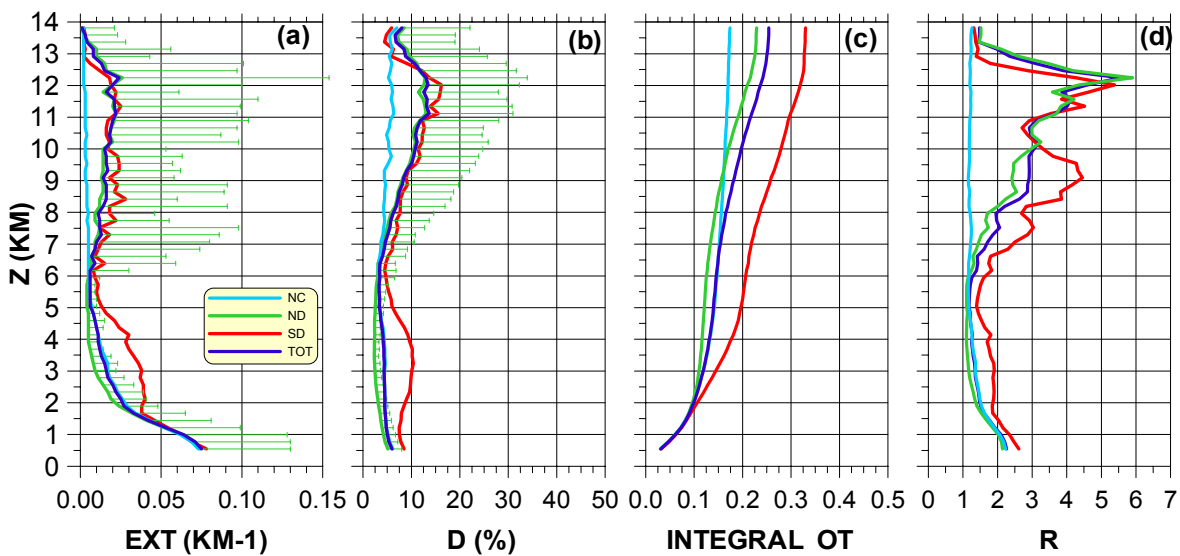

Fig. 3. Yearly average profiles (at $532 \mathrm{~nm}$ ) of: (a) extinction $\sigma_{a}$; (b) depolarization ratio D, (c) integral optical thickness OT(z) and (d) backscatter ratio R. Curve colors represent the total TOT (blue), no-dust ND (green), no-cirrus NC (pale blue) and Saharan dust SD (red) records, respectively (e.g. Table 1 for synopsis). Standard deviations associated to the ND mean curves are reported for both $\sigma_{a}$ and D profiles.

$30 \%$ higher averages ( $54 \%$ of days affected by cirrus clouds), with minimum occurrence in summer $(42 \%)$, and maximum occurrence in fall $(60 \%)$.

In order to verify the "Saharan" origin of the profiles included in the SD record, five-day backtrajectories ending over Rome, Italy were computed by means of the NOAA Air Resources Laboratory HYSPLIT code (Draxler and Rolph, 2003). In particular, for each of the 183 lidar profiles classified in the SD category, ensembles of ten backtrajectories ending in the region of maximum impact of dust events (3$4 \mathrm{~km}$ ) were computed. Properties of these 1830 backtrajectories are summarized in Fig. 2 in terms of a) geographical density of backtrajectory paths, and b) geographical density of backtrajectories transit (for at least three hours) within the atmospheric mixed-layer as computed by the HYSPLIT code (Draxler and Rolph, 2003). Densities in Fig. 2b are normalized to the total number of backtrajectories entering the mixed-layer. Figure 2a shows the typical advection pattern pertinent to SD profiles to mainly involve North Africa and Western Europe, then ruling out the alternative possibility of long-range transport from other areas. This plot also shows that, upon their final approach to our site, most of the trajectories transit over the Mediterranean sea. In addition to that, Fig. $2 \mathrm{~b}$ reveals that the region of most probable entrainment of mixed-layer air into the SD airmasses is the north African-Saharan one, with some minor input from Spain and the Mediterranean sea. However, we verified these latter airmasses did also enter the North-African mixed layer during their travel. Such cases are likely to result into a mixture of Saharan dust with other aerosols, still characterized by a strong depolarization signature (e.g. Gobbi et al., 2003). Overall, the backtrajectory analysis strongly supported the dominance of Saharan dust in the air masses catalogued as SD in this study.

\subsection{Yearly averages}

Annually-averaged $\sigma_{a}, \mathrm{D}$, integral OT, and $\mathrm{R}$ profiles are presented in Figs. 3a, b, c and d, respectively. In each plot, color coding of the curves represents the TOT (blue), ND (green), NC (pale blue) and SD (red) cases, respectively (e.g. Table 1). As an indication of the variability associated to measurements, standard deviations of the dust-less (ND) mean curves are reported in the extinction and depolarization plots (green error bars). In all plots, altitude is referred to mean sea level, the vertical resolution is $225 \mathrm{~m}$ and the first bin starts $300 \mathrm{~m}$ above the station level ( $130 \mathrm{~m}$ a.s.l.). In computing total OT, extinction of the lowermost $300 \mathrm{~m}$ is set equal to the first bin one, an assumption likely to lead to a small underestimation of this parameter.

In Figs. 3a and d, the dust-free (ND) annual profiles show aerosols in the lower troposphere to be confined below $4 \mathrm{~km}$, with $90 \%$ of the optical thickness of this layer residing below $2.5 \mathrm{~km}$ (Fig. 3c). Cirrus clouds formation is revealed by an increase in $\sigma_{a}, \mathrm{D}$, and $\mathrm{R}$ in the region between 6 and $14 \mathrm{~km}$. Therefore, in no-dust conditions a $2 \mathrm{~km}$ thick particulate-free gap is found between the PBL aerosol layer and the cirrus clouds region. Conversely, yearly-average dust-affected profiles (SD) present major departures from ND ones in the region $1.5-10 \mathrm{~km}$. As in the cirrus case, dust is clearly revealed by an increase in $\sigma_{a}, \mathrm{D}$, and $\mathrm{R}$. In particular, a two to six-fold increase in aerosol extinction is observed between 2 and $6 \mathrm{~km}$, while some increase in cirrus cloud extinction is noticed between 6 and $10 \mathrm{~km}$ (Fig. 3a).

It is also worth noticing that, in the region $7.5-10 \mathrm{~km}$, the yearly average extinction of cirrus clouds in the presence of dust (SD curve in Fig. 3a) results to be almost twice the dust-less one (ND curve). Due to the relative nature of the backscatter ratio, such an effect is even more evident when comparing the ND and SD yearly averages of R (Fig. 3d). 
Table 3. Contributions of lower troposphere aerosol (PBL), Saharan dust (SD) and cirrus clouds (CIR) to the total optical thickness of the $0-14 \mathrm{~km}$ region (TOT) in the yearly and seasonal analysis. Aerosol (i.e. PBL+SD) optical thickness is reported as AEROSOL for comparisons with coincidental AERONET sunphotometer (cloud and cirrus-screened data) measurements. Expected typical error is $\pm 35 \%$ for the lidar retrievals and \pm 0.02 for the sunphotometer data.

\begin{tabular}{cccccc}
\hline Class & Year & DJF & MAM & JJA & SON \\
\hline PBL & 0.13 & 0.11 & 0.13 & 0.16 & 0.12 \\
SD & 0.03 & 0.00 & 0.05 & 0.03 & 0.03 \\
CIR & 0.10 & 0.05 & 0.17 & 0.03 & 0.11 \\
TOT & 0.26 & 0.16 & 0.35 & 0.22 & 0.26 \\
AEROSOL (PBL+SD) & 0.16 & 0.11 & 0.18 & 0.19 & 0.15 \\
AERONET & 0.18 & 0.14 & 0.17 & 0.22 & 0.21 \\
\hline
\end{tabular}

Here, the SD backscatter $(\propto \mathrm{R}-1)$ in the cirrus region systematically exceeds the ND one between 6 and $10 \mathrm{~km}$, while being very similar above. Such increases in both extinction and backscatter were mostly generated in the period JuneNovember and are likely attributable to an increase in ice nuclei provided by dust grains, e.g. Sassen (2002). As a matter of fact, in this year dust was observed to reach up to $10 \mathrm{~km}$ during three events (May, June, July).

Total depolarization plots in Fig. $3 b$ indicate that the impact of particles non-sphericity on radiative transfer should be always considered in the cirrus region and during dust transport events. Furthermore, all depolarization profiles show an increase in the lower PBL, revealing a meaningful presence of non-spherical (possibly soil or combustiongenerated) particles over our site. Conversely, the small increase (to $\sim 5 \%$ ) in the NC curve depolarization ratio observed at altitudes above $6 \mathrm{~km}$ is mainly due to noise.

Overall, the yearly average OT of tropospheric particulate is 0.26 (TOT profile in Fig. 3c). PBL aerosol, dust and cirrus clouds contribute to that with $0.13(50 \%), 0.03(12 \%)$ and $0.10(38 \%)$, respectively. It is also worth noticing that the lower troposphere $(\mathrm{z}<6 \mathrm{~km})$ aerosol optical thickness gets almost doubled during dust events.

\subsection{Seasonal averages}

Seasonal average profiles of extinction, depolarization and integral OT are plotted in Fig. 4. Since the parameter of interest for climatic studies is extinction, backscatter ratio profiles have not been included in this figure to avoid overloading it. The winter plots (DJF, i.e. December 2001-February 2002) show no Saharan dust profiles since dust transport events did not occur during that period. Therefore, total (TOT) and dust-less (ND) profiles coincide in these plots. The lowest aerosol and cirrus contents are registered in this season, with an average total optical thickness of 0.16 (Fig. 4i) and PBL extinction rapidly reducing to $0.01 \mathrm{~km}^{-1}$ (here assumed as a threshold for background conditions) at $2 \mathrm{~km}$ (Fig. 4a). At the same time, extinction in the lower PBL reaches its maximum during this season (Fig. 4a). This is possibly due to both higher relative humidity (leading to enhanced growth of soluble particles) and to confinement of aerosols to the lower levels due to weaker convective activity. Such an explanation is also supported by the minimum depolarization values recorded at low altitude (Fig. 4e). In winter, the cirrus formation region extends between 8 and $13.5 \mathrm{~km}$, with average OT of the order of 0.05 (Fig. 4i).

The spring (MAM) record shows both dust and cirrus maximum activity. The average total OT of 0.35 (Fig. $4 \mathrm{j}$ ) is madeup by the contributions of PBL aerosols (0.13), dust (0.05) and cirrus (0.17). Figure $4 \mathrm{~b}$ shows the dust extinction (SD curve) to substantially exceed the ND profile in the region $1.5-5 \mathrm{~km}$. This translates into a strong impact of dust on the total spring extinction profile (TOT). In fact, while the ND extinction profile crosses the $0.01 \mathrm{~km}^{-1}$ value at $2.8 \mathrm{~km}$, the TOT one crosses it at $4.8 \mathrm{~km}$. As can be observed in Fig. $4 \mathrm{f}$, all the way up to $5.5 \mathrm{~km}$ dust depolarization is consistently larger than in the ND case, indicating a dominance of nonspherical particles in this region. A similar effect is found in the cirrus region, now extending between 6.5 and $13.5 \mathrm{~km}$.

Summer (JJA) conditions show a marked lifting of the PBL aerosol upper boundary and an increase in its OT, likely associated to a stronger convection. The threshold extinction value of $0.01 \mathrm{~km}^{-1}$ is now crossed at $3.8 \mathrm{~km}$ (ND curve in Fig. 4c) and PBL aerosol OT reaches maximum values of 0.16 , as opposed to the winter minimum of 0.08 (e.g. Figs. $4 \mathrm{k}$ and i). Nonetheless, a low cirrus activity leads to a total OT of 0.22 , i.e. smaller than the spring (0.35) and fall (0.26) ones. In this season, the cirrus contribution (0.03) to the total OT is of $13 \%$ (Fig. 4k), the lowest in the record. Figure $4 \mathrm{c}$ shows an evident impact of dust on the extinction profile between 2 and $6 \mathrm{~km}$, with a contribution of 0.03 to the total OT. Conversely, the dust (SD) extinction profile in the PBL below $1.7 \mathrm{~km}$ is systematically lower than the no-dust (ND) one. This effect (also visible in the MAM case), is possibly due to the warming and consequent stabilization of the PBL air characterizing Saharan events. In no-dust (ND) conditions, depolarization in the lower PBL (Fig. 4g) reaches the maximum value of the year (7\%), as opposed to minimum winter values of $4 \%$ (Fig. 4e). This behavior suggests both a stronger presence of crustal aerosols and a smaller RH-driven growth of soluble particles.

Similarly to spring, the fall (SON) record presents Saharan dust advection and strong cirrus activity. The ND and the TOT extinction profiles cross the $0.01 \mathrm{~km}^{-1}$ value at 2.5 and $3.5 \mathrm{~km}$, respectively. The dust (SD) contribution to total extinction clearly exceeds the ND profile in the region $0.5-5 \mathrm{~km}$ (Fig. 4d), i.e. in this season dust has a meaningful impact on the lower PBL too. With respect to the other seasons, the dust depolarization profile (SD in Fig. 4h) shows a lowering of the dust layer top and a systematic exceeding of the ND profile up to $10 \mathrm{~km}$. The average total optical depth of 0.26 (Fig. 41) is made-up by the sum of PBL aerosols (0.12), dust (0.03) and cirrus (0.11) contributions. In this season, cirrus clouds reside in the region $6-13.5 \mathrm{~km}$, representing $42 \%$ of total OT (Fig. 41). 

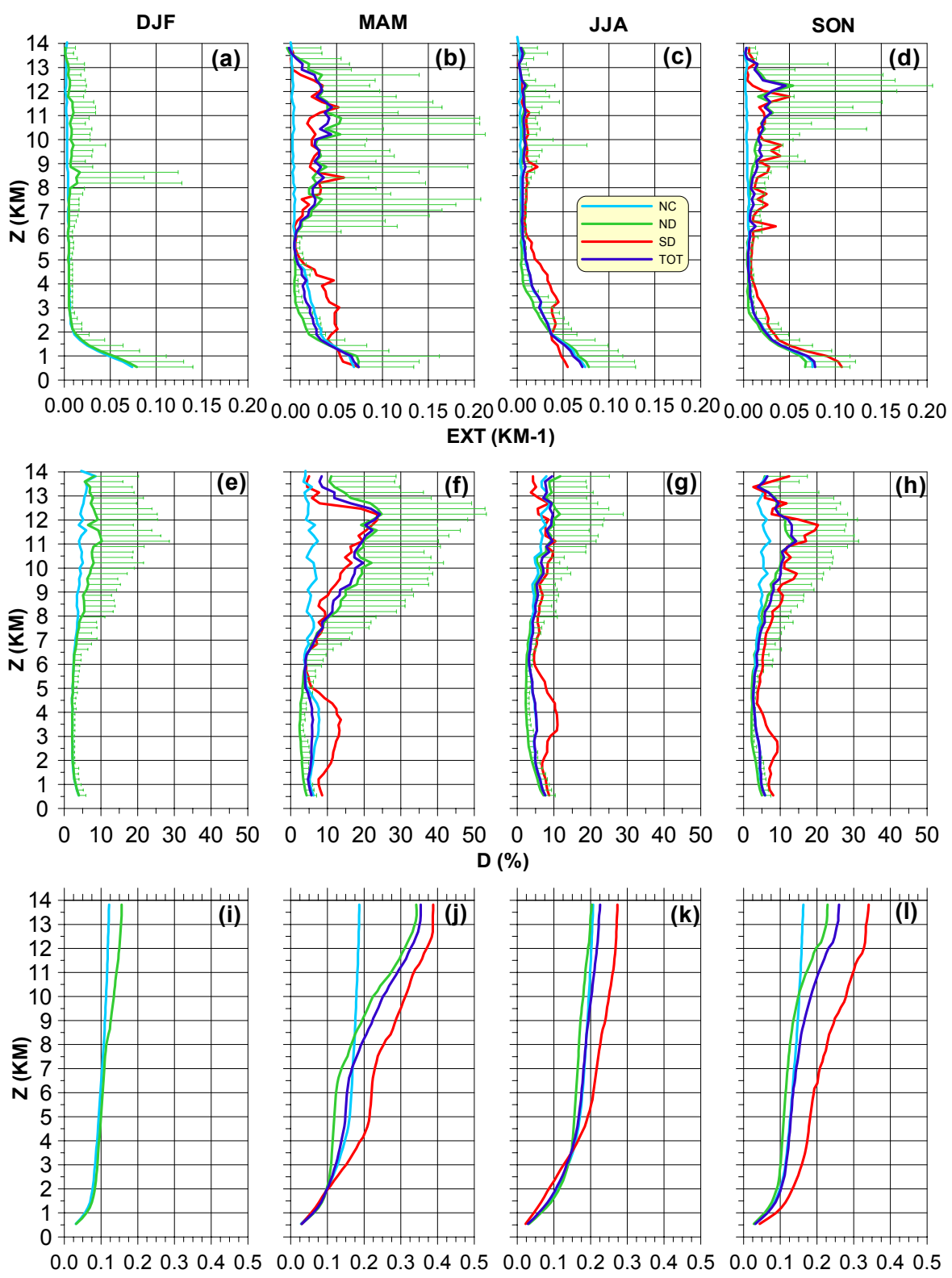

INTEGRAL OT

Fig. 4. Seasonal (columns) average profiles of $532 \mathrm{~nm}$ extinction $\sigma_{a}$ (first row), depolarization ratio D (second row) and integral optical thickness OT (third row). Curve colors represent the TOT (blue), ND (green), NC (pale blue) and SD (red) records, respectively (e.g. Table 1 for synopsis). Standard deviations associated to the ND mean curves are reported for both $\sigma_{a}$ and D profiles.

A summary of the yearly and seasonal average optical thickness OT is reported in Table 3. In this table we separated the contribution of boundary layer aerosols (PBL), Saharan dust particles (SD) and cirrus clouds (CIR) to the total (TOT) optical thickness. This partitioning allows to compare the lidar-derived aerosol contribution (i.e. $\mathrm{PBL}+\mathrm{SD}$ ) to the AERONET optical thickness measurements, which are screened to exclude both cloud and cirrus conditions. For this purpose, AERONET yearly and seasonal average OT for our site (Rome Tor Vergata) are also included in Table 3.
Overall, the comparison between lidar and sunphotometer aerosol OT is rather good and observations fall well within the retrievals typical errors of $35 \%$ and \pm 0.02 , respectively. As expected, some systematic underestimation, on average 0.02 , characterizes the lidar retrievals. This represents a departure of $11 \%$ from the OT yearly mean of 0.18 . As discussed in Sect. 3, this is likely due to the assumption of an aerosol extinction coefficient for the lowermost $300 \mathrm{~m}$ equal to the one of the above layer ( $\mathrm{z}=300-525 \mathrm{~m})$. However, the fall season presents a larger underestimation of 0.06. In this case, even if the sunphotometer mean OT $=0.21$ falls at the 
positive end of the lidar-derived OT range $(0.15 \pm 35 \%)$, we suspect such an above-average difference to be also due to a non-perfect cirrus-screening of the AERONET record. In fact, autumn was characterized by thinner, i.e. less detectable cirrus clouds with respect to spring 2001 (e.g. Figs. 4d and b).

\section{Conclusions}

One year (February 2001-February 2002) of lidar observations of tropospheric aerosols and cirrus clouds over Rome (Italy) has been presented and discussed. This record represents one of the few yearly climatologies of tropospheric profiles available in the scientific literature. With the exception of winter months, Saharan dust was found to represent an optically meaningful layer affecting the region between 1.5 and $6 \mathrm{~km}$, i.e. between PBL aerosols and cirrus clouds. Considered the ubiquitous transport of Saharan dust (e.g. Moulin et al., 1998), we expect this behavior to be rather common to the troposphere of Mediterranean regions. Saharan dust was detected in $20 \%$ of the 198 operational days ( $25 \%$ if considering cloudy ones as well), with maximum frequency in spring-summer 2001 (about 28\%) and no events in winter. On a yearly basis, dust accounted for $19 \%$ of the aerosol (cirrus-less) optical thickness. During the spring and fall dust events this contribution rose to $50 \%$.

Lower troposphere (PBL) aerosol OT was maximum in summer (0.16), and minimized in winter (0.08). Most of this aerosol was confined below 3.8 and $2 \mathrm{~km}$, respectively. Doubled depolarization values observed in the summer PBL, indicate a stronger impact on radiation of non-spherical particles with respect to winter. Cirrus clouds were detected in $45 \%$ of the operational days. Maximum and minimum incidence was registered in spring $(65 \%)$ and winter-summer (30\%), respectively. On the yearly average, cirrus and PBL aerosol contributions to OT were comparable. Presence of dust was often correlated with enhanced cirrus cloud extinction in the region $6-10 \mathrm{~km}$.

With the exception of winter months, these observations indicate a strong presence of non-spherical particulate matter at all tropospheric altitudes. This should be taken into account in both retrievals of aerosol properties performed by means of optical techniques and in the definition of the radiative properties of particulate matter suspended in the Earth atmosphere.

Acknowledgements. Part of this work has been carried out under the Italian Space Agency contract "GASTRAN". The authors gratefully acknowledge the NOAA Air Resources Laboratory (ARL) for the provision of the HYSPLIT transport and dispersion model.

Edited by: B. Kärcher

\section{References}

Balis, D., Papayannis, A., Galani, E., Marenco, F., Santacesaria, V., Hamonou, E., Chazette, P., Ziomas, I., and Zerefos, C.: Tropospheric Lidar aerosol measurements and sun photometric observations at Thessaloniki, Greece, Atmos. Env., 34, 925-932, 2000.

Barnaba, F. and Gobbi, G. P.: Lidar estimation of tropospheric aerosol extinction, surface area and volume: Maritime and desert-dust cases, J. Geophys. Res., 106 (D3), 3005-3018, 2001 (Correction in J. Geophys. Res., doi:10.1029/2002JD002340, 2002).

Barnaba, F. and Gobbi, G. P.: Modeling the aerosol extinction versus backscatter relationship for lidar applications: maritime and continental conditions, J. Atmos. Ocean. Tech., in press, 2004.

Draxler, R. R. and Rolph, G. D.: HYSPLIT (HYbrid Single-Particle Lagrangian Integrated Trajectory) Model access via NOAA ARL READY Website (http://www.arl.noaa.gov/ready/hysplit4.html), NOAA Air Resources Laboratory, Silver Spring, MD, 2003.

Duce, R. A., Unni, C. K., Ray, B. J., Prospero, J. M., Merrill, J. T.: Long range transport of soil dust from Asia to tropical North Pacific: Temporal variability, Science, 209, 1522-1524, 1980.

Del Guasta, M.: Daily cicles in urban aerosols observed in Florence (Italy) by means of an automatic 532-1064 nm Lidar, Atmos. Environ., 36, 2853-2865, 2002.

de Reus, M., Krejci, R., Williams, J., Fischer, H., Scheele, R., and Strom, J.: Vertical and horizontal distributions of the aerosol number concentration and size distribution over the northern Indian Ocean, J. Geophys. Res., 106, D22, 28 629-28 641, 2001.

De Tomasi, F. and Perrone, M. R.: Lidar measurements of tropospheric water vapor and aerosol profiles over southeastern Italy, J. Geophys. Res., 108, D9, 10.1029/2002JD002781, 2003.

Franke, K., Ansmann, A., Muller, D., Althausen, D., Wagner, F., and Scheele, R.: One-year observations of particle lidar ratio over the tropical Indian Ocean with Raman lidar, Geophys. Res. Lett., 28, 4559-4562, 2001.

Gobbi, G. P.: Lidar estimation of stratospheric aerosol properties: Surface, volume, and extinction to backscatter ratio, J. Geophys. Res., 100, 11 219-11 235, 1995.

Gobbi, G. P., Barnaba, F., Giorgi, R., Santacasa, A.: Altituderesolved properties of a Saharan-Dust event over the Mediterranean, Atmos. Environ., 34, 5119-5127, 2000.

Gobbi, G. P., Barnaba, F., Blumthaler, M., Labow, G., and Herman, J.: Observed effects of particles non-sphericity on the retrieval of marine and desert-dust aerosol optical depth by lidar, Atmos. Res., 61, 1-14, 2002.

Gobbi, G. P., Barnaba, F., Van Dingenen, R., Putaud, J. P., Mircea, M., and Facchini, M. C.: Lidar and in situ observations of continental and Saharan aerosol: closure analysis of particles optical and physical properties, Atmos. Chem. Phys., 3, 2161-2172, 2003.

Goldfarb, L., Keckhut, P., Chanin, M. L., and Hauchecorne, A.: Cirrus climatological results from lidar measurements at OHP (44ํ N-6 $\left.{ }^{\circ} \mathrm{E}\right)$, Geophys. Res. Lett., 28, 9, 1687-1690, 2001.

Hamonou, E., Chazette, P., Balis, D., Dulac, F., Schneider, X., Galani, E., Ancellett, G., and Papayannis, A.: Characterization of the vertical structure of Saharan dust export to the Mediterranean, J. Geophys. Res., 104, 22 257-22 270, 1999.

Hofmann, D. J.: Twenty years of balloon-borne tropospheric aerosol measurements at Laramie, Wyoming, J. Geophys. Res., 
98, 12 753-12 766, 1993.

Holben, B. N., Eck, T. F., Slutsker, I., Tanre, D., Buis, J. P., Setzer, A., Vermote, E., Reagan, J. A., Kaufman, Y., Nakajima, T., Lavenu, F., Jankowiak, I., and Smirnov, A.: AERONET - A federated instrument network and data archive for aerosol characterization, Rem. Sen. E., 66, 1-16, 1998.

Jaenicke, R.: Nucleation and atmospheric aerosol, edited by Fukuta, N. and Wagner, P. E., pp. 417, Deepak Publ., Hampton, Virginia, 1992.

Karyampudi, V. M., Palm, S. P., Reagan, J. A., Fang, H., Grant, W. B., Hoff, R. M., Moulin, C., Pierce, H. F., Torres, O., Browell, E. V., and Melfi, S. H.: Validation of the Saharan dust plume conceptual model using lidar, Meteosat and ECMWF data, Bull. Am. Meteorol. Soc., 80, 1045-1075, 1999.

Matthias, V. and Bosenberg, J.: Aerosol climatology for the planetary boundary layer derived from regular lidar measurements, Atmos. Res., 63, 221-245, 2002.

Measures, R. M: Laser Remote Sensing, J. Wiley, New York., 1984.

Mishchenko, M. I. and Sassen, K.: Depolarization of lidar returns by small ice crystals: An application to contrails, Geophys. Res. Lett., 25, 3, 309-312,1998.

Moulin, C., Lambert, C. E., Dayan, U., Masson, V., Ramonet, M., Bousquet, P., Legrand, M., Balkanski, Y. J., Guelle, W., Marticorena, B., Bergametti, G., and Dulac, F.: Satellite climatology of African dust transport in the Mediterranean atmosphere, J. Geophys. Res., 103, 13 137-13 144, 1998.

Muller, D., Mattis, I., Wandinger, U., Ansmann, A., and Althausen, D.: Saharan dust over a central European EARLINETAERONET site: Combined observations with Raman lidar and sun photometer, J. Geophys. Res., 108, D12, 4345, doi:10.1029/2002JD002918, 2003.

Murayama, T., Sugimoto, N., Uno, I., Kinoshita, K., Aoki, K., Hagiwara, N., Liu, Z., Matsui, I., Sakai, T., Shibata, T., Arao, K., Sohn, B., Won, J., Yoon, S., Li, T., Zhou, J., Hu, H., Abo, M., Iokibe, K., Koga, R., Iwasaka, Y.: Ground-based network observation of Asian dust events of April 1998 in east Asia, J. Geophys. Res., 106, D16, 18 345-18 360, 2001.
Penner, J. E., Andreae, M., Annegarn, H., Barrie, L., Feichter, J., Hegg, D., Jayaraman, A., Leaitch, R., Murphy, D., Nganga, J., and Pitari, G.: Aerosols, their Direct and Indirect Effects, In Climate Change 2001: The Scientific Basis, Cambridge University Press, Cambridge, UK, 2001.

Prospero, J. M., Glaccum, R. A., and Nees, R. T.: Atmospheric transport of soil dust from Africa to South America, Nature, 289, 570-572, 1983.

Prospero, J. M., Ginoux, P., Torres, O., Nicholson, S. E., and Gill, T. E.: Environmental characterization of global sources of atmospheric soil dust identified with the Nimbus 7 total ozone mapping spectrometer (TOMS) absorbing aerosol product, Rev. Geophys., 40, 1, 1002, doi:10.1029/2000RG000095, 2002.

Ramanathan, V., Crutzen, P. J., Kiehl, J. T., and Rosenfeld, D.: Aerosols, Climate, and the Hydrological Cycle, Science, 294, 2119-2124, 2001.

Russell, P. B., Swissler, T. J., and McCormick, M. P.: Methodology for error analysis and simulation of lidar aerosol measurements, Appl. Opt., 18, 3783-3797, 1979.

Sakai, T., Shibata, T., Kwon, S., Kim, Y., Tamura, K., and Iwasaka, Y.: Free tropospheric aerosol backscatter, depolarization ratio, and relative humidity measured with the Raman lidar at Nagoya in 1994-1997: contributions of aerosols from the Asian continent and the Pacific ocean, Atmos. Env., 34, 431-442, 2000.

Sassen, K.: The polarization lidar technique for cloud research: A review and current assessment, Bull. Am. Met. Soc., 72, 18481866, 1991.

Sassen, K: Indirect climate forcing over the western US from Asian dust storms, Geophys. Res. Lett., 29, 10, 10.1029/2001GL014051, 2002.

Schneider, J. and Eixmann, R.: Three years of routine Raman lidar measurements of tropospheric aerosols: Backscattering, extinction and residual layer height, Atmos. Chem. Phys., 2, 313-323, 2002.

Stull, R. B.: An introduction to boundary layer meteorology, 666 pp., Kluwer Acad. Publ., Dordrecht, 1988. 